\title{
Comparative In Vitro Equivalence Evaluation of Some Loratadine Generic Tablets Marketed in Bangladesh
}

\author{
Tasnim Motaher Oishi, Sanjida Munna, Zainab Noor, Sajan Das, Rumana \\ Akhter, Sumaiya Huque and Mohammad Shahriar* \\ Pharmaceutical Technology Research Laboratory, Department of Pharmacy, University of Asia Pacific, Dhaka, \\ Bangladesh
}

\begin{abstract}
Loratadine is a potent, rapidly effective and long-acting non-sedative, histamine $\mathrm{H}_{1}$ receptor antagonist, with anti-allergic properties. The purpose of this research work was to evaluate the pharmaceutical equivalent of six different brands of loratadine $10 \mathrm{mg}$ tablets using various pharmacopoeial and nonpharmacopoeial tests with special landmark on in vitro dissolution study and with different price ranges purchased from retail pharmacies of Bangladesh. All brands complied with the official specification for friability, uniformity of weight and disintegration time but four brands did not comply with the official specification for hardness. Assay of loratadine tablets revealed that all samples contained $86.65-95.02 \%$ of labeled potency. Drug release was satisfactory for all brands, since more than $96.76 \%$ of the loratadine was dissolved in the medium within an hour of the test. The dissolution profiles were compared with the use of model independent approaches of difference factor and similarity factor, showing that all brands are similar with brand L3 and can be used interchangeably.
\end{abstract}

Keywords: Loratadine, In vitro equivalence, Dissolution, Difference factor $\left(f_{1}\right)$, Similarity factor $\left(f_{2}\right)$

\section{Introduction}

The quantitative evaluation and assessment of a tablet's chemical, physical and bioavailability properties are important in the design of tablets and to monitor product quality. These properties are important since chemical breakdown or interactions between tablet components may alter the physical tablet properties, and greatly affect the bioavailability of the tablet system. There are various standards that have been set in the various pharmacopoeias regarding the quality of pharmaceutical tablets. These include the diameter, size, shape, thickness, weight, hardness, friability, disintegration and dissolution characters [1-2].

The most frequently used second-generation $\mathrm{H}_{1}$ receptor antagonists are desloratadine, loratadine, fexofenadine, cetirizine and levocetirizine [3]. These are differentiated by organic structure into the piperazine class, consisting of cetirizine and levocetirizine and the piperadine class, which includes desloratadine, loratadine, fexofenadine [4]. However, the use of traditional antihistamines such as diphenhydramine, chlorpheniramine, triprolidine and promethazine is often associated with a number of unwanted side-effects of which sedation is the most pronounced [5-7].

Loratadine is a potent long-acting, long half-life, second generation nonsedating tricyclic antihistamine drug with selective peripheral $\mathrm{H}_{1}$-receptor antagonist activity [8], which prevents and suppresses seasonal and perennial allergic rhinitis, allergic dermatitis, urticaria and occular allergy with no autonomic anticholinergic effects in humans [9-11]. In contrast to the first-generation antihistamines, loratadine does not cross the bloodbrain barrier, shows selectivity when used at therapeutic concentrations and reveals high affinity to peripheral $\mathrm{H}_{1}$ receptors, allowing avoiding induction of somnolence [12-15]. Loratadine is contraindicated on patients who have hypersensitivity or idiosyncrasy to its component. Less common side effects may include nervousness, wheezing, hyperkinesias, dysphonia, dizziness, dyspepsia, pharyngitis etc.

Loratadine $\left(\mathrm{C}_{22} \mathrm{H}_{23} \mathrm{ClN}_{2} \mathrm{O}_{2}\right)$, chemically 4-(8-chloro-5,6-dihydro-11 H-benzo-[5,6] cyclohepta [1,2-b] pyridin11-ylidene)-1-piperidinecarboxylic acid ethyl ester [16], is white crystalline powder with melting point of $131^{\circ} \mathrm{C}$ to $137^{\circ} \mathrm{C}$, molecular weight of 382.89 , virtually insoluble in water, poorly soluble in diethyl ether but well soluble in such organic solvents as ethanol (760 g/L), methanol, acetone, 2- propanol and chloroform [12, 17].

According to the Biopharmaceutical Classification System (BCS) drug substances are classified to four classes upon their solubility and permeability [18-19]. Loratadine is classified in the Biopharmaceutics Classification System (BCS) as a Class II drug i.e. low solubility and high permeability compound. Low solubility of the drug limits its bioavailability; despite having good absorption, only about $40 \%$ of the dose enters into the systemic circulation.

Generic substitution is the prescribing different brand or an unbranded drug which contains the same API at similar strength and dosage form [20]. Branded drug products of top pharmaceutical companies are better in 
terms of efficacy as well as they are costly. As a consequence, patients from low-income countries can hardly afford those [3].

The goal of this study was to investigate the physical quality control parameters of marketed loratadine tablets in Bangladesh. These parameters included diameter, thickness, weight variation, hardness, friability with special landmark on disintegration and dissolution study due to their mountainous significance in predicting bioavailability and product quality.

\subsection{Collection of sample products:}

\section{Materials And Methods}

Standard of loratadine was a kind gift from ACI Pharmaceutical Ltd, Bangladesh. Loratadine tablets (10 mg) of six different brands were purchased from registered pharmacy stores of Dhaka, Bangladesh. The samples were properly checked for their manufacturing license numbers, batch numbers, manufacturing, expiry dates and for ethical concerns, the tablets were randomly coded as L1, L2, L3, L4, L5 and L6 so that the identity of the manufacturer can be blinded (Table. 1). The shape, size and color of different branded tablets were subjected to visual inspection at the very beginning of research work.

\subsection{Physiochemical parameters:}

Rational use of medicines requires that "patients receive medications appropriate to their clinical needs, in doses that meet their own individual requirements, for an adequate period of time, and at the lowest cost to them and their community" [21]. The reason behind poor patient compliance include poor availability, a lack of affordability, poor prescribing practices and a lack of patient adherence [22]. The purchase of medicines contributes significantly to the health care budget of developing countries. Due the resources of the National Health Services are limited which can be considered as the tip of iceberg, so it is the need of time to keep eye on the quality and cost of the drugs that are available in the markets. The label information of six different brands of loratadine tablets $(10 \mathrm{mg})$ is represented in Table. 1.

Table. 1. Label information of six different brands of loratadine tablets

\begin{tabular}{|c|c|c|c|c|c|}
\hline $\begin{array}{c}\text { Brand } \\
\text { code }\end{array}$ & Mfg. date & Exp. date & $\begin{array}{c}\text { Pack size } \\
\text { found }\end{array}$ & $\begin{array}{c}\text { Price of pack } \\
\text { found (BDT) }\end{array}$ & $\begin{array}{c}\text { Price / 10 units } \\
\text { (BDT) }\end{array}$ \\
\hline L1 & December 2015 & December 2018 & 100 & 250 & 25 \\
\hline L2 & November 2015 & November 2018 & 100 & 300 & 30 \\
\hline L3 & February 2016 & February 2018 & 100 & 400 & 40 \\
\hline L4 & February 2016 & February 2018 & 30 & 90.60 & 30.2 \\
\hline L5 & June 2016 & June 2018 & 100 & 301 & 30.1 \\
\hline L6 & January 2015 & January 2018 & 50 & 125 & 25 \\
\hline
\end{tabular}

\subsection{Diameter and thickness inspection:}

Ten tablets from each brand were selected for diameter and thickness test. Diameter and thickness were determined by using digital slide caliper. Mean thickness, diameter and their standard deviations (SD) were calculated.

\subsection{Hardness test:}

Crushing strength $(\mathrm{N})$ was determined with an automatic hardness tester (VEEGO, INDIA). Ten tablets were randomly selected from each brand and the pressure required to crush were recorded.

\subsection{Friability test:}

Ten tablets from each brand were weighed and subjected to rotation by employing a VEEGO friabilator (VFT-2, India) which was operated at 25 RPM for 4 minutes and then all tablets were weighted after 100 revolutions.

\subsection{Weight variation:}

For weight variation ten tablets from each brand were weighed individually using an analytical balance (TE214S, Sartorious Germany).

\subsection{Standard assay preparation:}

The powder equivalent to $100 \mathrm{mg}$ of loratadine was taken and dissolved in phosphate buffer (PH 6.8). Then it was diluted to produce a final concentration of $0.016 \mathrm{mg} / \mathrm{ml}(16 \mu \mathrm{g} / \mathrm{ml})$ for working solution. Absorbance values were then measured at the maximum wavelength $(\lambda$ max) of loratadine of these concentrations using a UV-VIS spectrophotometer (UV-1700, Shimadzu, Japan). Maximum wavelength ( $\lambda$ max) was obtained by scanning samples at different wavelength ranging from 200 to $400 \mathrm{~nm}$ and it was found to be $280 \mathrm{~nm}$.

\subsection{Disintegration test:}

Disintegration test is a measure of the time required under a given set of conditions for a group of tablets to disintegrate into particles which will pass through a 10 mesh screen. It has to be pointed out that a product which fails disintegration will presumably fail dissolution criteria [23]. Six tablets from each brand were employed for the test in distilled water at $37^{\circ} \mathrm{C}$ using a tablet disintegration tester ED-20 (Electrolab, Mumbai, 
India) as per condition described by United State Pharmacopeia, 2014 [24]. The disintegration time (DT) was noted down and by definition, it's the time taken for the entire tablet to disintegrate completely.

\subsection{Measurement of potency:}

Analysis of drug potency in tablets is to evaluate the tablets potential for efficacy by monitoring the presence of drug in dosage form and also requisite for the establishment of stability data. The standard was prepared in the same concentration as for the dissolution testing. Sample was prepared by weighing and crushing 10 tablets, transferring amount of drug powder equivalent to $20 \mathrm{mg}$ in $\mathrm{pH} 1.2 \mathrm{buffer}$ solutions and placing it in sonicator. The portion of solution was filtered and the filtrate was suitably diluted. Absorbance was taken at $280 \mathrm{~nm}$ by using UV- visible spectrophotometer. Finally the potency of different tablets was determined by using the following equation:

\subsection{Dissolution test:}

$$
\text { Potency }=\frac{\text { Drug content }}{\text { Therapeutic value }} \times 100
$$

The dissolution test was undertaken for six randomly selected tablets using dissolution apparatus paddle (VEEGO, India). The dissolution medium was $900 \mathrm{ml}$ of phosphate buffer (PH 6.8) which was maintained at $37 \pm 0.5{ }^{\circ} \mathrm{C}$. Rotations were 50 revolutions per minute. $10 \mathrm{ml}$ sample was withdrawn after 45 minutes, and was diluted to $200 \mathrm{ml}$ by using $0.1 \mathrm{M}$ sodium hydroxide to obtain a solution containing $0.00075 \% \mathrm{w} / \mathrm{v}$ of loratadine. Standard solution was prepared accordingly. Absorbance was measured at $280 \mathrm{~nm}$ with $0.1 \mathrm{M}$ sodium hydroxide in reference cell according to British Pharmacopeia, 2013 [25]. To determine the concentration of sample, help from the standard curve of pure API was taken. Using the $Y=m X+C$ equation, sample concentration was calculated.

\subsection{Price fluctuation:}

\section{Results and Discussion}

Price, manufacturing and expiry date of loratadine were observed in the drug outlets on single visit during medicine collections. As the variation in the price has been observed from as much as 25 to 40 BDT per 10 units (Table 1), while there was no significant variation in the quality of the tested drugs. Hence it may be suggested that the pharmaceutical outcomes are promising too in terms of most economically available drug.

\subsection{Diameter and thickness inspection:}

By monitoring the diameter and thickness at regular intervals during the production may prevent potential problems related to tablet weight and to ensure uniformity in tablets appearance and fitting into the containers for packaging process at an early stage [26, 21]. Among six brands, the average diameter was found to be between the ranges of (6.06-8.03) $\mathrm{mm}$ and the average thickness was found to be between the ranges of (2.57-3.18) mm which makes it difficult for patient's points of view (Table. 2).

\subsection{Hardness test:}

Hardness has impact on disintegration and perhaps more significantly, to the drug release rate. Monitoring of tablet hardness is important for drug products that possess real or potential bioavailability problems or that are sensitive to altered drug release profile due to the compression force. The testing of tablet hardness and friability plays a pivotal role in both product development and subsequent quality control because high hardness values may result in increased disintegration times and decreased dissolution times. As opposed to this situation, high friability values may be observed in case of low hardness values. Hardness is referred to as non-compendial test. Among six brands, brand L4 had the highest percentage of hardness (46.1N) whereas brand L1 had the lowest percentage of hardness $(15.4 \mathrm{~N})$ (Table. 2). A force of about $40 \mathrm{~N}$ is the minimum requirement for a satisfactory tablet [27] but brands L1, L2, L3 and L5 did not comply with this requirement but their disintegration time was found satisfactory, therefore, the batches were considered as of good quality (Table. 2).

Table. 2. A summary of the quality control tests undertaken on different brands of loratadine tablets

\begin{tabular}{|c|c|c|c|c|c|c|c|}
\hline $\begin{array}{c}\text { Brand } \\
\text { Code }\end{array}$ & $\begin{array}{c}\text { Diameter* } \\
(\mathbf{m m})\end{array}$ & $\begin{array}{c}\text { Thickness* } \\
\mathbf{( m m )}\end{array}$ & $\begin{array}{c}\text { Friability* } \\
\mathbf{( \% )}\end{array}$ & $\begin{array}{c}\text { Hardness* } \\
\mathbf{( N )}\end{array}$ & $\begin{array}{c}\text { Weight } \\
\text { Deviation* } \\
\text { (gm) }\end{array}$ & DT* (min) & Potency* (\%) \\
\hline L1 & $6.11 \pm 0.02$ & $2.91 \pm 0.05$ & 0.44 & $15.4 \pm 5.80$ & $0.09 \pm 0.27$ & $2.25 \pm 0.03$ & 86.65 \\
\hline L2 & $6.43 \pm 0.04$ & $2.57 \pm 0.03$ & 0.11 & $17.6 \pm 1.43$ & $0.10 \pm 0.01$ & $1.52 \pm 0.08$ & 91.83 \\
\hline L3 & $7.08 \pm 0.13$ & $2.80 \pm 0.02$ & 0.08 & $28.5 \pm 2.80$ & $0.13 \pm 0.01$ & $2.33 \pm 0.03$ & 90.87 \\
\hline L4 & $8.03 \pm 0.02$ & $2.69 \pm 0.06$ & 0.18 & $46.1 \pm 5.15$ & $0.18 \pm 0.01$ & $0.35 \pm 0.02$ & 95.02 \\
\hline L5 & $7.08 \pm 0.05$ & $3.18 \pm 0.05$ & 0.15 & $28.9 \pm 2.56$ & $0.14 \pm 0.01$ & $6.53 \pm 0.01$ & 92.95 \\
\hline L6 & $6.06 \pm 0.03$ & $3.06 \pm 0.04$ & 0.30 & $40.3 \pm 2.83$ & $0.14 \pm 0.05$ & $1.43 \pm 0.02$ & 91.99 \\
\hline
\end{tabular}

*Values are expressed as mean $\pm \mathrm{SD}$ 


\subsection{Friability test:}

Friability test is now included in the United States Pharmacopeia, 1995 [28] as a compendial test. The compendial specification for friability is $1 \%$. Usually harder the tablets less will be the percentage friability and vice versa [29]. It was found that 6 different brand of loratadine tablet were in accordance with the stated USP guideline (Table. 2 ).

\subsection{Weight variation:}

Uniformity of weight serves as a monitor to good manufacturing practice as well as amount of the active pharmaceutical ingredient contained in the formulation [29]. The weight variation test would be a satisfactory method of determining the drug content uniformity of tablets if the tablets were all or essentially all (90 to 95\%) active ingredient, or if the uniformity of the drug distribution in the granulation or powder form which the tablets were made were perfect [2]. According to USP, the limit of deviation is $\pm 10 \%$ for tablets weighing $130 \mathrm{mg}$ or less and not more than two tablets should cross the single limit and none of them should cross the double of the limit. The weight variation for all the tablets used in this study showed compliance with the stated official specifications (Table. 2).

\subsection{Disintegration test:}

Tablets is expected to break down into smaller particles or granules inside the stomach within a reasonable time to release the active ingredient into the body as the process will facilitate further dissolution in the biological fluids before gastrointestinal absorption followed by distribution, metabolism and excretion, which is the fate of drug. According to BP specification, film coated tablets should disintegrate within $30 \mathrm{~min}$, while the USP specifies that both uncoated and film coated tablets should disintegrate within 30 min. From table 2 it can be demonstrated that, all the brands of loratadine met the official criteria. Here, brand L5 took maximum time of 6.53 minute and brand L4 took the minimum time of 0.35 minute to disintegrate (Table. 2).

\subsection{Potency:}

Loratadine is an INN drug; no official specification is available yet. For highly potent, low-dose drugs this range is usually not less than $90 \%$ and not more than $110 \%$ of the labeled amount. Potency of all the brands was found within $86.65 \%$ - 95.02\%. All the brands met this specification except brand L1, which released 86.65\% of drug after an hour (Table. 2).

\subsection{Dissolution test:}

Inter-brand comparison showed that brand L3 had maximum drug release within the first 10 minutes (77.90\%) of the in vitro dissolution test, while brand L1 released $74.96 \%$ of drug after this time. From the table 3 , it can be demonstrated that tablets of all the six brands have more than $85 \%$ of drug release after 60 minutes and tablets of brand L3 released $96.76 \%$ percent of drug which was the highest and tablets of brand L1 released $89.48 \%$ percent of drug which was the lowest of all six brands. Since the standard specification of percent of drug release is not less than $85 \%$, it can be assumed that all the brands possessed good dissolution profile although the brands were manufactured by different companies using different excipients in different ratio (Table. 3).

Table. 3. Dissolution profile of six brands of loratadine tablets

\begin{tabular}{|c|c|c|c|c|c|c|}
\hline \multirow[t]{2}{*}{ Time (min) } & \multicolumn{6}{|c|}{ \% Drug Release } \\
\hline & Brand L1* & Brand L2* & Brand L3* & Brand L4* & Brand L5* & Brand L6* \\
\hline 0 & $0 \pm 0$ & $0 \pm 0$ & $0 \pm 0$ & $0 \pm 0$ & $0 \pm 0$ & $0 \pm 0$ \\
\hline 10 & $74.96 \pm 0.67$ & $75.88 \pm 0.37$ & $77.90 \pm 0.48$ & $72.98 \pm 0.75$ & $75.40 \pm 0.51$ & $75.73 \pm 0.57$ \\
\hline 20 & $78.29 \pm 0.76$ & $78.29 \pm 0.72$ & $81.23 \pm 0.51$ & $78.68 \pm 0.75$ & $79.16 \pm 0.54$ & $78.92 \pm 0.77$ \\
\hline 30 & $79.74 \pm 0.70$ & $83.88 \pm 1.07$ & $89.48 \pm 0.66$ & $81.81 \pm 0.51$ & $82.24 \pm 0.63$ & $84.99 \pm 0.81$ \\
\hline 40 & $82.58 \pm 0.71$ & $89.72 \pm 0.67$ & $93.43 \pm 0.54$ & $84.66 \pm 0.47$ & $84.95 \pm 0.68$ & $87.21 \pm 0.96$ \\
\hline 50 & $85.04 \pm 0.63$ & $91.99 \pm 0.54$ & $95.51 \pm 0.34$ & $89.57 \pm 0.62$ & $88.18 \pm 0.54$ & $90.25 \pm 0.54$ \\
\hline 60 & $89.48 \pm 0.44$ & $94.21 \pm 0.60$ & $96.76 \pm 0.34$ & $92.32 \pm 0.50$ & $90.93 \pm 0.52$ & $92.57 \pm 0.63$ \\
\hline
\end{tabular}

*Values are expressed as mean $\pm \mathrm{SD}$

\subsection{Comparison of dissolution data:}

Difference factor $\left(f_{1}\right)$ and similarity factor $\left(f_{2}\right)$ were calculated to compare the dissolution profile. The following equations were used to calculate $f_{1}$ and $f_{2}$. Where $n$ is the number of time points, $R_{t}$ is the dissolution value of reference product at time $t$ and $T_{t}$ is the dissolution value for the test product at time $t$. Similarity factor $\left(f_{2}\right)$ has been adopted by FDA and the European Agency for the Evaluation of Medicinal Products by the Committee for Proprietary Medicinal Products (CPMP) to compare dissolution profile. According to the FDA guidance [30] dissolution profiles are similar if $f_{1}$ values are between 0 and 15 and $\mathrm{f}_{2}$ values are between 50 and 100. 


$$
\begin{aligned}
\mathrm{f}_{1} & =\left\{\frac{\sum_{i=1}^{\mathrm{n}}\left|\mathrm{R}_{\mathrm{t}}-\mathrm{T}_{\mathrm{t}}\right|}{\sum_{\mathrm{i}=1}^{\mathrm{n}} \mathrm{R}_{\mathrm{t}}}\right\} \times \times 100 \\
\mathrm{f}_{2} & =50 \log \left\{\left(1+\frac{1}{\mathrm{n}} \sum_{\mathrm{i}=1}^{\mathrm{n}}\left(\mathrm{R}_{\mathrm{t}}-\mathrm{T}_{\mathrm{t}}\right)^{2}\right)^{-0.5} \times 100\right\}
\end{aligned}
$$

Table. 4. $\mathrm{f}_{1}$ and $\mathrm{f}_{2}$ of six brands of loratadine tablets tested

\begin{tabular}{|c|c|c|}
\hline Pair Comparison & Difference Factor $\left(\mathbf{f}_{\mathbf{1}}\right)$ & Similarity Factor $\left(\mathbf{f}_{\mathbf{2}}\right)$ \\
\hline L1 vs. L3 & 8.28 & 54.44 \\
\hline L2 vs. L3 & 3.81 & 71.51 \\
\hline L4 vs. L3 & 6.42 & 60.53 \\
\hline L5 vs. L3 & 6.26 & 60.48 \\
\hline L6 vs. L3 & 4.61 & 67.46 \\
\hline
\end{tabular}

Table. 4 represent the $f_{1}, f_{2}$ values of different brands in respect of brand L3 as a reference brand. For all brands, $\mathrm{f}_{1}$ was less than 15 and $\mathrm{f}_{2}$ value was more than 50 . So brands of all loratadine tablets are similar with brand L3 and can be used interchangeably.

\section{Conclusion}

During the formulation and manufacturing of a drug product it is very important to keep a check on each and every step. In vitro tests must be done in order to compare the multi brand generic molecules for having good therapeutic activity. Implementation of these approaches can reduce the time and cost required for manufacturing, while improving quality control. In vitro dissolution test in three $\mathrm{pH}$ levels and probably in vivo test may be required for final comments regarding the quality of marketed brands of loratadine.

\section{References}

[1]. Maswadeh HM, Al-Jarbou AN. An investigation on physical quality control parameters of dietary supplements tablets commercially available on the Kingdom of Saudi Arabia. International Journal of Applied Research in Natural Products, 4(3), 2011, 22-26.

[2]. L. Lachman, H, Lieberman, J, Kanig. The theory and practice of industrial pharmacy (Varghese publication house, 1987).

[3]. Huque S, Brishti NR, Noor M, Das S, Akhter R, Gorapi MZH, Tanni KA, Shahriar M. Comparative in vitro equivalence evaluation of some Desloratadine generic tablets marketed in Bangladesh. International Journal of Applied Research, 3(2), 2017, $288-293$.

[4]. Devillier P, Roche N, Faisy C. Clinical pharmacokinetics and pharmacodynamics of desloratadine, fexofenadine and levocetirizine: a comparative review. Clinical Pharmacokinetics, 47(4), 2010, 217-230.

[5]. Mattila MJ, Matilla M, Konno K. Acute and sub acute actions on human performance and interactions with diazepam of temelastine and diphenhydramine. European Journal of Clinical Pharmacology, 31, 1986, 291-298.

[6]. Goetz DW, Jacobson MM, Apaliski SJ, Repperger DW, Martin ME. Objective antihistamine side effects are mitigated by evening dosing of hydroxyzine. Annals of Allergy, 67, 1991, 448-454.

[7]. Brookhuis KA, De Vries G, De Waard D. Acute and subchronic effects of histamine $\left(\mathrm{H}_{1}\right)$ receptor antagonist ebastine in 10, 20 and 30mg dose, and triprolidine 10mg on car driving performance. British Journal of Clinical Pharmacology, 36, 1993, 67-70.

[8]. Patel BN, Sharma N, Sanyal M, Shrivastav PS. LC-MS-ESI for the determination of loratadine and descarboethoxyloratadine in human plasma. Journal of Chromatographic Science, 48(1), 2010, 35-44.

[9]. Bedard PM, Del Carpio J, Gutkowski A. Comparison of efficacy and safety of SCH 29851, terfenadine and placebo in treatment of seasonal rhinitis (Abstract 29). Annals of Allergy, 55, 1985, 233.

[10]. Batenhorst RL, Batenhorst AS, Graves DA, Foster TS, Kung M, Gural RP, Amkraut HJ. Pharmacologic evaluation of loratadine (SCH 29851), chlorpheniramine and placebo. European Journal of Clinical Pharmacology, 31, 1986, 247-250.

[11]. Villani FJ, Magatti CV, Vashi DB, Wong J, Popper TL. N-substituted 11-[4- piperidylene)-5,6-dihydro-11H-benzo-[5,6]cyclohepta-[1,2-b] pyridines: Antihistamines with no sedating liability. Arzneimittel-Forschung, 36, 1986, 1311-1314.

[12]. Nachajski MJ, Kokosza A, Kołodziejczyk M, Zgoda MM. Second-generation antihistamines in the treatment of allergies on the example of loratadine. Military Pharmacy and Medicine, 1, 2012, 61 - 65.

[13]. Ghoneim MM, Mabrouk MM, Hassanein AM, Tawfik A. Polarographic behaviour of loratadine and its direct determination in pharmaceutical formulation and human plasma by cathodic adsorptive stripping voltammetry. Journal of Pharmaceutical and Biomedical Analysis, 25, 2001, 933-939.

[14]. Amsellem C, Czarlewski W, Lagarde M, Pacheco Y. Inhibitory effect of loratadine on leukotriene B4 production by Neutrophils either alone or during interaction with human airway epithelial cells. Pulmonary Pharmacology \& Therapeutics, 11, 1998, 245-252.

[15]. Menardo JL, Horak F, Danzig MR, Czarlewski W. A review of loratadine in the treatment of patients with allergic bronchial asthma. Clinical Therapeutics, 19(6), 1997, 1278-1293.

[16]. Belaich S, Bruttmann G, DeGreef H, Lachapelle JM, Paul E, Pedrali P, Tennstedt D. Comparative effects of loratadine and terfenadine in the treatment of chronic idiopathic urticaria, Annals of Allergy, 64(2 Pt 2), 1990, 191-194.

[17]. Prenner BM, Capano D, Harris AG. Efficacy and tolerability of loratadine versus fexofenadine in the treatment of seasonal allergic rhinitis: a doubleblind comparison with crossover treatment of nonresponders. Clinical Therapeutics, 22(6), 2000, 760-69.

[18]. Yasir M, Asif M, Kumar A, Aggarval A. Biopharmaceutical Classification System: An Account. International Journal PharmTech, Research, 2(3), 2010, 1681-1690.

[19]. Dahan A, Miller JM, Amidon GL. Prediction of solubility and permeability class membership: Provisional BCS classification of the world's top oral drugs. American Association of Pharmaceutical Scientists Journal, 11(4), 2009, 740-746.

[20]. Posner J, Griffin JP. Generic substitution. British Journal of Clinical Pharmacology, 72(5), 2011, 731-732. 
[21]. Bano R, Gauhar S, Naqvi SBS, Mahmood S. Pharmaceutical evaluation of different brands of levofloxacin tablets (250 mg) available in local market of Karachi (Pakistan). International Journal of Current Pharmaceutical Research, 3, 2011, 15-22.

[22]. Mendis S, Abegunde D, Yusuf S, Ebrahim S, Shaper G, Ghannem H, Shengelia B. WHO study on Prevention of REcurrences of Myocardial Infarction and StrokE (WHO-PREMISE). Bulletin World Health Organization, 83(11), 2005, 820-828.

[23]. Du J, Hoag SW. Characterization of excipient and tableting factors that influence folic acid dissolution, friability, and breaking strength of oil- and water-soluble multivitamin with mineral tablets. Drug Development and Industrial Pharmacy, 29, 2003, 11341147.

[24]. United State Pharmacopoeia. United States Pharmacopoeial Convention. Rockville, Maryland, 2014.

[25]. British Pharmacopeia. Her Majesty’s Stationary Office, London, 2013.

[26]. Akgeyik E, Kaynak MS, Çelebier M, Altınöz S, Şahin S. Evaluation of pharmaceutical quality of conventional dosage forms containing paracetamol and caffeine available in the Turkish drug market. Dissolution Technology. 2016; 23(2), 2016, 36-41.

[27]. Allen LV, Popovich NG, Ansel HC. (2011). Ansel's pharmaceutical dosage forms and drug delivery systems (8 ${ }^{\text {th }}$ ed). Lippincott Williams \& Wilkins, Philadelphia.

[28]. US Pharmacopeia National Formulary USP 23/NF 18. United States Pharmacopeial Convention. Inc., Rockville, MD, 1995.

[29]. Oishi TS, Nimmi I, Islam SMA. Comparative in vitro Bioequivalence Analysis of Some Generic Tablets of Atorvastatin, a BCS Class II Compound. Bangladesh Pharmaceutical Journal, 14(1), 2011, 61-66.

[30]. Waiver of in vivo bioavailability and bioequivalence studies for immediate-release solid oral dosage forms based on a biopharmaceutics classification system; guidance for industry; U.S. Department of Health and Human Services, Food and Drug Administration, Center for Drug Evaluation and Research (CDER), U.S. Government Printing Office: Washington, DC, 2000. 